\title{
Association of melanocortin 4 receptor gene variation with satiation and gastric emptying in overweight and obese adults
}

\author{
Andres Acosta $\cdot$ Michael Camilleri $\cdot$ \\ Andrea Shin · Paula Carlson · Duane Burton • \\ Jessica O'Neill · Deborah Eckert • Alan R. Zinsmeister
}

Received: 16 August 2013/ Accepted: 11 January 2014/Published online: 24 January 2014

(c) Springer-Verlag Berlin Heidelberg 2014

\begin{abstract}
Melanocortin 4 receptor (MC4R) has a major role in energy homeostasis. The rs17782313 polymorphism, mapped $188 \mathrm{~kb}$ downstream from MC4R, has been associated with satiety, higher body mass index (BMI) and total calorie intake in adults. To assess the association of rs17782313 with gastric functions, satiation, or satiety, we studied 178 predominantly Caucasian overweight and obese people: 120 females, 58 males; mean BMI $33.4 \pm 5.3 \mathrm{~kg} / \mathrm{m}^{2}(\mathrm{SD})$; age $37.7 \pm 11.2$ years. Quantitative traits assessed were gastric emptying (GE) of solids and liquids; fasting and postprandial gastric volume; satiation by maximum tolerated volume and 4 symptoms by 100-mm visual analog scales (VAS); and satiety by ad libitum buffet meal. Associations of genotype and quantitative traits were assessed by analysis of covariance (using gender and BMI as covariates), based on a dominant [TC $(n=72)-\mathrm{CC}(n=12)$ vs. TT $(n=94)]$ genetic model. rs17782313(C) was associated with postprandial satiation symptoms (median $\Delta$ total VAS $26.5 \mathrm{~mm}$, $p=0.036$ ), reduced proportion of solid GE at $2 \mathrm{~h}$ (median $\Delta 6.7 \%, p=0.008$ ) and $4 \mathrm{~h}$ (median $\triangle 3.2 \%$, $p=0.006$ ), and longer $t_{1 / 2}$ (median $\Delta 6 \mathrm{~min}, p=0.034$ ). Associations of rs 17782313 with obesity may be explained
\end{abstract}

A. Acosta · M. Camilleri $(\bowtie) \cdot$ A. Shin $\cdot$ P. Carlson ·

D. Burton · J. O'Neill · D. Eckert

Clinical Enteric Neuroscience Translational and

Epidemiological Research (C.E.N.T.E.R.), Division of

Gastroenterology and Hepatology, Department of Medicine,

Mayo Clinic, Charlton 8-110, 200 First St. S.W., Rochester,

MN 55905, USA

e-mail: camilleri.michael@mayo.edu

\section{A. R. Zinsmeister}

Division of Biomedical Statistics and Informatics, Department of Health Sciences Research, College of Medicine, Mayo Clinic,

Rochester, MN, USA by reduced satiation and GE. The role of MC4R mechanisms in satiation and gastric function deserves further study.

Keywords Melanocortin 4 receptor (MC4R) . rs17782313 - Satiation · Gastric emptying - Obesity

\section{Introduction}

Melanocortin (MC) pathway plays a major role in energy homeostasis. The melanocortin pathway is derived from products of the proopiomelanocortin (POMC) gene that is $\alpha$-MSH, $\beta-\mathrm{MSH}, \gamma-\mathrm{MSH}$, and ACTH (Adan et al. 2006). These peptides are agonists of the melanocortin receptors. The melanocortin 4 receptor (MC4R) is a key regulator of energy homeostasis, inducing energy expenditure and decreasing food intake. MC4R is a G protein-coupled receptor which is activated by $\alpha$-MSH and blocked by Agouti-related peptide (Hinney et al. 2013). MC4R has been associated with key components of nutrient absorption, lipid metabolism, energy expenditure, thermogenesis, adiposity, insulin secretion, food intake, and appetite (Adan et al. 2006). Moreover, the MC pathway interacts with other key hormones or pathways such as leptin, 5-HT (Zhou et al. 2007), NPY, AGRP, POMC (Biebermann et al. 2012), and ANS (Rossi et al. 2011; Sohn et al. 2013) in the hypothalamus and brainstem (Loos 2011), GLP-1 pathway (Gautron et al. 2010), CCK, and vagal afferent fibers (Guan et al. 2012).

MC4R deficiency is the most common monogenic cause of obesity [up to $6 \%$ (Loos 2011)]. There are 166 SNPs or mutations of $M C 4 R$ reported thus far, mainly in obese subjects (Frayling et al. 2007; Hinney et al. 2013). The functional MC4R mutations (missense, frameshift, 
nonsense, or deletion) are associated with severe childhood obesity (Hinney et al. 2013). Conversely, the MC4R V103I and $\mathrm{I} 251 \mathrm{~L}$ polymorphisms are associated with reduced risk of obesity. The polymorphism rs17782313, mapped $188 \mathrm{~kb}$ downstream from $M C 4 R$, is strongly associated with obesity and higher body mass index (BMI) (Frayling et al. 2007; Loos et al. 2008; Vogel et al. 2011) alone or in association with other obesity-related genes, such as FTO (Marcadenti et al. 2013). A GWAS study of 60,000 adults indicated that rs17782313(C) alleles are associated with higher BMI, with even greater effect in children. The average increase in BMI was $0.22 \mathrm{~kg} / \mathrm{m}^{2}$. The polymorphism rs17782313 is associated with satiety in American, European, and Chilean children (Beckers et al. 2011; Czerwensky et al. 2013; Qi et al. 2008; Stutzmann et al. 2009; Valladares et al. 2010; Xi et al. 2012) as well as with higher intake of total calories, fat, and protein (Beckers et al. 2011; Loos 2011; Qi et al. 2008; Scherag et al. 2010; Valette et al. 2013). In a systematic review of 61 studies (involving 80,957 obese and 220,223 controls), rs17782313 polymorphism was significantly associated with obesity risk (OR 1.18, $95 \%$ CI 1.15-1.21, $p=0.001$ ) (Xi et al. 2012). The effects of MC4R and rs17782313 polymorphisms on eating behavior were recently reviewed by Valette et al. (2012) and Hinney et al. 2013 These large population-based studies focused on body mass phenotype and indicated a relationship between rs17782313 and obesity. In addition, there are mechanistic insights that suggest the genetic variation rs17782313 may influence 'reward' mechanisms, particularly in females. A recent study showed that, in female homozygous carriers of the risk allele, there is significant increase in gray matter volume in the right amygdala (a region known to influence eating behavior) and in the right hippocampus, which is crucial for memory formation and learning (Horstmann et al. 2013). Similarly, there is evidence that cerebral insulin resistance may contribute to the obesity effect of rs17782313(C) (Tschritter et al. 2011). It is unclear whether rs17782313 polymorphism alters gastric motor function, satiation, and satiety. Thus, the aim of our study was to determine whether rs17782313 polymorphism is associated with gastric motor functions, satiation, or satiety in overweight and obese people.

\section{Methods and procedures}

\section{Participants}

The method of recruitment for our study of 178 predominantly Caucasian overweight or obese participants was similar to that described elsewhere (Papathanasopoulos et al. 2010). We obtained approval from the Mayo Clinic
Institutional Review Board to use stored DNA in accordance with written informed consent from participants in a study on the genetic predisposition to obesity (NIH DK67071). The main inclusion criteria were men or women with BMI above $25 \mathrm{~kg} / \mathrm{m}^{2}$, age $18-65$ years, residing within 150 miles of Rochester, Minnesota, and not on current treatment for other diseases. Exclusion criteria were a positive history of any systemic disease that could affect gastrointestinal motility, and use of medications that alter gastrointestinal motility, appetite, or absorption (e.g., orlistat). Permissible medications were multivitamins, birth control pills, estrogen, and thyroxine replacement, all at stable doses for at least 30 days prior to the quantitative studies. Women of childbearing potential had a negative pregnancy test within $48 \mathrm{~h}$ before any radioisotopes were administered.

\section{Experimental protocol}

The study was approved by the Mayo Clinic Institutional Review Board, and all participants gave written informed consent following thorough explanation of the study details. On different days, they presented to the Mayo Clinic Clinical Research Unit at 7:00 a.m. after an 8-h fasting period and underwent a dual-isotope $\left[{ }^{99 \mathrm{~m}} \mathrm{Tc}\right.$ (technetium) and ${ }^{111}$ In (indium)] gastric emptying (GE) scintigraphic study, a nutrient drink satiation test, and a gastric accommodation study by means of single-photon emission computed tomography (SPECT), in that order (Papathanasopoulos et al. 2010). Gastric emptying and SPECT studies were performed at least $72 \mathrm{~h}$ apart to avoid downscatter interference by ${ }^{111}$ In from the meal ingested during the GE study with the measurement of gastric volume $(\mathrm{GV})$ by ${ }^{99 \mathrm{~m}} \mathrm{Tc}-\mathrm{SPECT}$.

\section{Gastric emptying study with scintigraphy}

Participants ingested a solid and liquid caloric meal (total calories: $296 \mathrm{kcal}, 32 \%$ protein, $35 \%$ fat, $33 \%$ carbohydrate) in which both phases of the meal were radiolabeled: $1.0 \mathrm{mCi}{ }^{99 \mathrm{~m}} \mathrm{Tc}$-sulfur colloid was added to two raw eggs during the scrambling and cooking process. The scrambled eggs were served on one slice of bread with $240 \mathrm{~mL}$ of skim milk labeled with $0.1 \mathrm{mCi}{ }^{111}$ In-DTPA. Anterior and posterior gamma camera images were obtained immediately after radiolabeled meal ingestion, then every $15 \mathrm{~min}$ for the first $2 \mathrm{~h}$, followed by every $30 \mathrm{~min}$ for the next $2 \mathrm{~h}$ [total of $4 \mathrm{~h}$ after the radiolabeled meal (Papathanasopoulos et al. 2010)]. Data were analyzed as in previous studies (Vazquez Roque et al. 2006). Geometric mean of counts in gastric regions of interest on anterior and posterior images was used (after correction for radioisotope decay and downscatter from the ${ }^{111}$ In to the 
${ }^{99 \mathrm{~m}} \mathrm{Tc}$ window) to estimate the proportion of ${ }^{99 \mathrm{~m}} \mathrm{Tc}$ or ${ }^{111} \mathrm{In}$ emptied from the stomach at each time point. Gastric emptying $t_{1 / 2}$ for solids and liquids, defined as the time which elapses until $50 \%$ of the meal is emptied, was estimated by linear interpolation of the data at each time point.

Gastric volume and accommodation assessment with ${ }^{99 m}$ Tc-SPECT

We measured GV during fasting and 30 min after $300 \mathrm{~mL}$ of Ensure ${ }^{\circledR}$ (316 kcal) using noninvasive SPECT. The method has been previously validated (Cremonini et al. 2002). Intravenous injection of ${ }^{99 \mathrm{~m}} \mathrm{Tc}$ sodium pertechnetate, which is taken up by the parietal and nonparietal cells of the gastric mucosa, allows visualization of the stomach wall. Tomographic images of the gastric wall were obtained throughout the long axis of the stomach using a dual-head gamma camera (Siemens MSII, Malvern, PA, USA) that rotates around the body. The radiolabeled circumference of the gastric wall (rather than the intra-gastric content) was thus identified. Using the AVW 3.0 (Biomedical Imaging, Mayo Foundation, Rochester, MN, USA) image processing libraries, a three-dimensional rendering of the stomach was obtained and its volume $(\mathrm{mL})$ calculated. There is high intra-observer reproducibility to measure $\mathrm{GV}$ with this technique (Bouras et al. 2002). The inter-individual coefficient of variation $\left(\mathrm{COV}_{\text {INTER }}\right)$ for all subjects in a study from our laboratory ( $n=433$ ) was $32.6 \%$ fasting, $16.0 \%$ fed, and $19.0 \%$ for the $\Delta$ volume fed-fasting. The intraindividual $\mathrm{COV}$ ( $\left.\mathrm{COV}_{\text {INTRA }}\right)$ for 47 subjects with repeat estimates of $\mathrm{GV}$ was $37.0 \%$ fasting, $17.6 \% \mathrm{fed}$, and $22.0 \%$ for the $\Delta$ volume fed-fasting. COV $_{\text {INTRA }}$ was stable over a period from 2 to 60 months (De Schepper et al. 2004). There were no significant differences by gender.

\section{Nutrient drink satiation test}

We used a validated nutrient drink test (Breen et al. 2011) to measure satiation and postprandial symptoms when drinking a liquid nutrient at a rate of $120 \mathrm{~mL}$ every $4 \mathrm{~min}$ (Ensure $^{\circledR}: 1 \mathrm{kcal} \mathrm{mL}^{-1}, 11 \%$ fat, $73 \%$ carbohydrate and $16 \%$ protein). Participants scored the level of fullness or satiation using a scale combining verbal descriptors and numbers $(0=$ no symptoms; $5=$ maximum or unbearable fullness/satiation). Nutrient intake was stopped when subjects reached the score of 5, with maximum satiation indicated by the maximum tolerated volume of Ensure ${ }^{\circledR}$. Postprandial symptoms of fullness, nausea, bloating, and pain were recorded $30 \mathrm{~min}$ after the meal using $100-\mathrm{mm}$ horizontal visual analog scales, with the words 'none' and 'worst ever' anchored at the left and right ends of the lines for each symptom.
Satiety measurement by ad libitum meal

Four hours after ingesting $300 \mathrm{~mL}$ liquid nutrient as part of the SPECT study, participants were invited to eat, over a 30-min period, a standard ad libitum meal that included vegetable lasagna [Stouffers ${ }^{\circledR}$, Nestle USA, Inc., Solon, $\mathrm{OH}$; nutritional analysis of each 326-g box: $420 \mathrm{kcal}, 17 \mathrm{~g}$ protein (16\% of energy), $38 \mathrm{~g}$ carbohydrate (37\% of energy), and $22 \mathrm{~g}$ fat (47\% of energy)], vanilla pudding [Hunts ${ }^{\circledR}$, Kraft Foods North America, Tarrytown, NY; nutritional analysis of each 99-g carton: $130 \mathrm{kcal}, 1 \mathrm{~g}$ protein (3\% of energy), $21 \mathrm{~g}$ carbohydrate $(65 \%$ of energy), and $4.5 \mathrm{~g}$ fat (32\% of energy)], and skim milk [nutritional analysis of each 236-mL carton: $90 \mathrm{kcal}, 8 \mathrm{~g}$ protein (36\% of energy), $13 \mathrm{~g}$ carbohydrate (64\% of energy), and $0 \mathrm{~g}$ fat]. The total amount ( $\mathrm{g}$ and $\mathrm{kcal}$ ) of food consumed at the ad libitum meal was analyzed by using validated software (ProNutra version $3.0^{\circledR}$; Viocare Technologies Inc, Princeton, NJ, USA).

\section{Determination of genotypes}

DNA was extracted from whole blood as previously described (Papathanasopoulos et al. 2010). Genotyping of rs17782313 was performed using Taqman ${ }^{\circledR}$ SNP genotyping assays (2012) in accordance with the manufacturer's instructions (Taqman ${ }^{\circledR}$ SNP Genotyping Assays 2012).

\section{Statistical analysis}

All data are presented as mean \pm SEM, medians \pm IQR, or percentages, as noted. The univariate associations of subject characteristics and response measures (e.g., GE $t_{1 / 2}$ values) with overall genotype were assessed using Fisher's exact test (e.g., association with categorical variables like gender) and analysis of covariance (ANCOVA), adjusting for gender and BMI, to assess the association with the quantitative traits and the genotype, with exception of the liquid GE which was assessed using the Kruskal-Wallis test. These analyses were done using the dominant genetic model that pools the minor allele homozygote with the heterozygote genotype: TC plus CC versus TT for the rs17782313 genotypes. The grouping was based on prior demonstration that the disease-predisposing allele is the $\mathrm{C}$ allele for the MC4R rs17782313 genotype (Loos et al. 2008). This assumes the single allele has a biologic effect.

A sample size assessment for detecting clinically relevant associations for the rs17782313 genotype was examined by estimating the differences between two groups (i.e., assuming a dominant genetic model) that could be detected given the observed variation in the measured responses and the number of subjects that were 
obtained in each genotype group [TC $(n=72)-\mathrm{CC}$ $(n=12)$ vs. TT $(n=94)]$. The differences between groups that could be detected with approximately $80 \%$ power (two-sided $\alpha$ level of 0.05) using a two-sample $t$ test [assuming the listed pooled standard deviation (SD)] were described previously (Vazquez-Roque et al. 2011). Except for GE (two endpoints), each physiologic response corresponds to a distinct null hypothesis (e.g., association of genotype of interest with nutrient drink test maximum tolerated volume, i.e., satiation). Therefore, we did not correct for assessing associations with multiple intermediate phenotypes. A $p$ value $<0.05$ was considered to be statistically significant except in the assessment of the association between genotype and GE ( $\alpha$ level of 0.025 in view of two comparisons for solids and liquids). The analyses used the $\mathrm{SAS}^{\circledR}$ statistical package (version 9.3, SAS Institute, Cary, NC, USA).

\section{Results}

\section{Subject characteristics}

Demographic characteristics of individuals in each genotype group are outlined in Table 1 . We recruited 178 overweight and obese participants, 120 females and 58 males, with a mean BMI of $33.4 \pm 5.3(\mathrm{SD}) \mathrm{kg} / \mathrm{m}^{2}$ and age of $37.7+11.2$ years. The participants were predominantly Caucasians. There were no significant overall associations of any genotype with age, gender, race, BMI, or weight.

\section{Relationship of rs17782313 genotype with satiation}

rs17782313(C) was associated with postprandial satiation symptom score (median $\Delta$ between genotype groups total symptom score $26.5 \mathrm{~mm}, p=0.036$ ), but there was no significant association with maximal tolerated volume of the liquid nutrient drink. The postprandial satiation symptom score difference was mainly due to a significant

Table 1 Subjects' characteristics by genotype (summary values are mean \pm SEM, unless otherwise indicated)

\begin{tabular}{|c|c|c|c|}
\hline \multirow[t]{2}{*}{ Genotype } & \multicolumn{3}{|l|}{ rs 17782313} \\
\hline & TT & $\mathrm{TC}$ & $\mathrm{CC}$ \\
\hline$n$ & 94 & 72 & 12 \\
\hline Females $(\%)$ & 69.15 & 63.89 & 75 \\
\hline Race [caucasian (\%)] & 93.62 & 88.89 & 100 \\
\hline Age (years) & $38.23 \pm 1.26$ & $37.28 \pm 1.2$ & $35.8 \pm 2.3$ \\
\hline BMI $\left(\mathrm{kg} / \mathrm{m}^{2}\right)$ & $33.47 \pm 0.58$ & $33.52 \pm 0.62$ & $32.42 \pm 0.99$ \\
\hline
\end{tabular}

Fisher's exact test applied for gender; Kruskal-Wallis test for age, weight, and BMI association with postprandial nausea (median $\Delta 9.5 \mathrm{~mm}$, $p=0.016)$. There was no association with postprandial fullness, bloating, or pain (Table 2).

Relationship of rs17782313 genotype with gastric motor functions

rs17782313(C) was associated with delayed proportion of solid GE at $2 \mathrm{~h}$ (median $\Delta 6.7 \% ; p=0.008$ ) and $4 \mathrm{~h}$ (median $\Delta 3.2 \% ; p=0.006$ ), and $t_{1 / 2}$ (median $\Delta 6 \mathrm{~min}$; $p=0.034$ ) (Table 3 ). There were no significant associations of rs17782313 with GE of liquids, fasting GV and accommodation volume, and satiety (Table 4).

\section{Discussion}

In population studies, the gene variation rs17782313 (nearest gene, $M C 4 R$ ) has been associated with higher BMI and food intake (Beckers et al. 2011; Qi et al. 2008; Stutzmann et al. 2009; Valladares et al. 2010; Vogel et al. 2011; Xi et al. 2012). In this study in humans, we explored the associations of this gene variation with gastric motor function, satiation, and satiety. The gene variation rs17782313(C) was significantly associated with satiation and GE of solids. There were no associations with GE of liquids, GV and accommodation, and satiety.

$\mathrm{MC} 4 \mathrm{R}$ is a key regulator of energy homeostasis, inducing energy expenditure and decreasing food intake. We report here that individuals with $\mathrm{C}$ allele (CC or TC genotype) rs17782313 polymorphism have $\sim 25 \%$ less postprandial satiation symptoms compared with the TT genotype after ingestion of a fully satiating meal, individualized for each participant. The difference in postprandial satiation symptoms was explained by individuals with the $\mathrm{C}$ allele having $60 \%$ less postprandial nausea when compared with the TT allele. There were no significant differences in the other postprandial satiation symptoms of fullness, bloating, and pain.

Interestingly, individuals with the $\mathrm{C}$ alleles had a maximal tolerated volume on average $87.5 \mathrm{~mL}$ lower than individual with the $\mathrm{T}$ allele. This difference $(<6.7 \%$ of the average maximum tolerated volume) did not reach statistical significance, but it is equivalent to $91.9 \mathrm{kcal}_{\text {(Ensure }}{ }^{\circledR}$ $1.05 \mathrm{kcal}$ per $\mathrm{mL}$ ). Our findings may suggest that the rs 17782313(C) polymorphism is associated with a decrease in postprandial satiation symptoms, suggesting that such individuals' response to a high-caloric meal may be better tolerated with less satiation than in individuals with a $\mathrm{T}$ allele. Postprandial satiation symptoms are related to meal termination and subsequent increase in appetite and caloric intake in the next meal. Thus, it is conceivable that individuals with rs17782313(C) polymorphism may ingest 
Table 2 Association of rs17782313 with satiation [results are median (IQR); associations assessed using the dominant genetic model (TT vs. CC and TC)]

\begin{tabular}{|c|c|c|c|c|c|c|c|}
\hline \multirow[t]{2}{*}{ rs17782313 } & \multirow[t]{2}{*}{$n$} & \multicolumn{6}{|c|}{ Postprandial satiation with maximal intake of liquid nutrient drink } \\
\hline & & MTV (mL) & Nausea & Fullness & Bloating & Pain & Total symptom score $(\max 400)$ \\
\hline TT & 94 & $1,302(948-1,425)$ & $24(5-62)^{\mathrm{a}}$ & $76(65-84)$ & $59(42-76)$ & $11.5(2-43)$ & $183(131-244)^{\mathrm{a}}$ \\
\hline $\mathrm{TC}$ & 72 & $1,185(977-1,422)$ & $15(1-50)$ & $72(60-82)$ & $54(36-69)$ & $11.5(0-31)$ & $161(126-207)$ \\
\hline $\mathrm{CC}$ & 12 & $1,244(1,066-1,516)$ & $14(6-28)$ & $71.5(64-76)$ & $53(34-65)$ & $5.5(2-11)$ & $151(128-165)$ \\
\hline $\mathrm{CC}-\mathrm{TC}$ & 84 & $1,185(1,005-1,422)$ & $15(2-46)$ & $72(60-81)$ & $54(36-68)$ & $8(0-28)$ & $156(126-199)$ \\
\hline
\end{tabular}

a $\mathrm{TT}$ versus $\mathrm{CC}+\mathrm{TC}$ groups by the dominant genetic model $p<0.05$

Table 3 Association of rs17782313 with gastric emptying of solids [results are median (IQR); associations assessed using the dominant genetic model (TT vs. CC/TC)]

\begin{tabular}{|c|c|c|c|c|}
\hline \multirow[t]{2}{*}{ rs 17782313} & \multirow[t]{2}{*}{$n$} & \multicolumn{3}{|l|}{ Gastric emptying solids } \\
\hline & & Proportion emptied by $2 \mathrm{~h}$ & Proportion emptied by $4 \mathrm{~h}$ & GE $t_{1 / 2}(\min )$ \\
\hline TT & 94 & $0.65(0.33-0.73)^{\mathrm{a}}$ & $0.97(0.95-0.99)^{\mathrm{a}}$ & $93.75(78-108)^{\mathrm{a}}$ \\
\hline $\mathrm{TC}$ & 72 & $0.60(0.51-0.70)$ & $0.96(0.92-0.98)$ & $99(86-118)$ \\
\hline $\mathrm{CC}$ & 12 & $0.56(0.50-0.70)$ & $0.93(0.90-0.98)$ & $100(86-121)$ \\
\hline $\mathrm{CC}-\mathrm{TC}$ & 84 & $0.60(0.50-0.71)$ & $0.95(0.92-0.98)$ & $100(86-119)$ \\
\hline
\end{tabular}

${ }^{\mathrm{a}} \mathrm{TT}$ versus $\mathrm{CC}+\mathrm{TC}, p<0.05$

Table 4 Association of rs17782313 with gastric emptying of liquids, gastric volume and accommodation, and satiety [results are median (IQR); associations assessed using the dominant genetic model]

\begin{tabular}{|c|c|c|c|}
\hline & \multicolumn{3}{|l|}{ rs17782313 } \\
\hline & $\mathrm{CC}$ & $\mathrm{CT}$ & TT \\
\hline Liquid GE 2 h (\%) & $0.89(0.86-0.94)$ & $0.89(0.86-0.92)$ & $0.90(0.88-0.94)$ \\
\hline Liquid GE $t_{1 / 2}(\min )$ & $17.4(12-22)$ & $17.4(14-23)$ & $15.7(13-22)$ \\
\hline Gastric volume fasting $(\mathrm{mL})$ & $238(185-290)$ & $266(230-329)$ & $267(228-319)$ \\
\hline Gastric volume fed $(\mathrm{mL})$ & $784(691-840)$ & $749.7(665-857)$ & $768(702-830)$ \\
\hline Gastric accommodation volume $(\Delta)$ & $495(462-607)$ & $467(420-551)$ & $491(419-550)$ \\
\hline Buffet meal (kcal) & $898(769-1,156)$ & $911(777-1,134)$ & $905(721-1,170)$ \\
\hline Buffet meal protein $(\%)$ & $22.3(22-24)$ & $23.6(22-25)$ & $22.4(21-24)$ \\
\hline Buffet meal fat $(\%)$ & $23.6(22-30)$ & $24(22-25)$ & $23.7(22-26)$ \\
\hline Buffet meal carbohydrate (\%) & $51.9(49-56)$ & $53.2(50-55)$ & $53.7(51-56)$ \\
\hline
\end{tabular}

more frequent meals, resulting in a higher daily caloric intake. Therefore, our findings extend the observations of prior population studies (Beckers et al. 2011; Qi et al. 2008; Stutzmann et al. 2009; Valladares et al. 2010; Vogel et al. 2011; $\mathrm{Xi}$ et al. 2012) and suggest that rs17782313(C) polymorphism may be associated with higher BMI due to decreased postprandial satiation symptoms.

Additionally, we report that the individuals with rs17782313(C) polymorphism had a 6.7 and $3.2 \%$ slower GE of solids at 2 and $4 \mathrm{~h}$, respectively, when compared with individual with the TT genotype. This was also evident in the 6-min difference in GE $t_{1 / 2}$ of solids (being slower in those with $\mathrm{C}$ allele compared with the TT genotype). The origin of postprandial symptoms in obese individuals may reflect either delay in GE or increased sensitivity or acceleration of GE, the latter being presumed to result in symptoms from intestinal distention (DelgadoAros et al. 2004). The finding of slightly slower, though statistically significant, GE could be consistent with the hypothesis that reduced emptying in those individuals with the $\mathrm{C}$ allele results in less symptoms from intestinal distension. Further studies are needed to explore these hypotheses, including assessing the calorie intake over prolonged periods, not just an ad libitum meal, in the different groups based on rs17782313 variation. 
Our findings could support the evidence that, in rodents, MC4R plays a major role in mediating satiation and food intake (Gautron et al. 2010) and that the MC4R pathway activates the area postrema in the brainstem (Rowland et al. 2010), which is the major regulator of the nausea and vomiting center. In rodents, MC4R agonists, such as melanotan-II (MTII), activate the area postrema in wildtype mice, but not in MC4R knockout mice, suggesting a lack of neural activation in the knockout mice (Rowland et al. 2010). Our main findings suggest that rs $17782313(\mathrm{C})$ polymorphism decreases the postprandial nausea response to a high-caloric meal ingested to maximum tolerance, which may induce nausea or vomiting as a normal response. Although the functional effects of this polymorphism have not been demonstrated in an animal model, our data are consistent with the hypothesis that rs17782313(C) polymorphism may down-regulate the MC4R function, reduce neural activation (as observed in MC4R knockout mice), decrease the nausea in response to overeating, decrease postprandial satiation and, ultimately, could lead to increased BMI in humans.

Additionally, MC4R rs17782313(C) polymorphism may alter the expression of MC4R receptors located on efferent vagal neurons; these MC4R receptors on vagal neurons are known to be associated with increased satiation and regulation of gastric function (Balthasar et al. 2005; Fan et al. 2004; Gautron et al. 2010; Wan et al. 2008). Further studies are needed to determine whether MC4R agonist targeting obesity and metabolic syndrome would have different effects depending on the genotype of the rs17782313 polymorphisms.

In summary, our data suggest that genetic variation of rs 17782313, mapped $188 \mathrm{~kb}$ downstream from $M C 4 R$, is associated with satiation and gastric motor function. The rs $17782313(\mathrm{C})$ polymorphism confirms the concept that the genetic variations in $M C 4 R$ may predispose to obesity. The combination of studies of genotype-intermediate phenotype associated with satiation may help understand the effect of MC4R in obesity and the potential for MC4R agonists in the treatment for obesity.

Acknowledgments The authors thank Mrs. Cindy Stanislav for secretarial assistance. Dr. Camilleri is supported by NIH RO1DK067071 for studies in obesity.

Conflict of interest The authors declare no conflicts.

\section{References}

Adan R, Tiesjema B, Hillebrand J, la Fleur S, Kas M, de Krom M (2006) The MC4 receptor and control of appetite. $\mathrm{Br} \mathrm{J}$ Pharmacol 149:815-827

Balthasar N, Dalgaard LT, Lee CE, Yu J, Funahashi H, Williams T et al (2005) Divergence of melanocortin pathways in the control of food intake and energy expenditure. Cell 123:493-505
Beckers S, Zegers D, de Freitas F, Mertens I, Van Gaal L, Van Hul W (2011) Association study of MC4R with complex obesity and replication of the rs17782313 association signal. Mol Genet Metab 103:71-75

Biebermann H, Kühnen P, Kleinau G, Krude H (2012) The neuroendocrine circuitry controlled by POMC, MSH, and AGRP. Handbook Exper Pharmacol 209:47-75

Bouras E, Delgado-Aros S, Camilleri M, Castillo EJ, Burton DD, Thomforde GM et al (2002) SPECT imaging of the stomach: comparison with barostat, and effects of sex, age, body mass index, and fundoplication. Single photon emission computed tomography. Gut 51:781-786

Breen M, Camilleri M, Burton D, Zinsmeister A (2011) Performance characteristics of the measurement of gastric volume using single photon emission computed tomography. Neurogastroenterol Motil 23:308-315

Cremonini F, Mullan B, Camilleri M, Burton D, Rank M (2002) Performance characteristics of scintigraphic transit measurements for studies of experimental therapies. Aliment Pharmacol Ther 16:1781-1790

Czerwensky F, Leucht S, Steimer W (2013) Association of the common MC4R rs17782313 polymorphism with antipsychoticrelated weight gain. J Clin Psychopharmacol 33:74-79

De Schepper H, Camilleri M, Cremonini F, Foxx-Orenstein A, Burton D (2004) Comparison of gastric volumes in response to isocaloric liquid and mixed meals in humans. Neurogastroenterol Motil 16:567-573

Delgado-Aros S, Cremonini F, Castillo JE, Chial HJ, Burton DD, Ferber I et al (2004) Independent influences of body mass and gastric volumes on satiation in humans. Gastroenterology 126:432-440

Fan W, Ellacott KL, Halatchev IG, Takahashi K, Yu P, Cone RD (2004) Cholecystokinin-mediated suppression of feeding involves the brainstem melanocortin system. Nature Neurosci 7:335-336

Frayling TM, Timpson NJ et al (2007) A common variant in the FTO gene is associated with body mass index and predisposes to childhood and adult obesity. Science 316(5826):889-894

Gautron L, Lee C, Funahashi H, Friedman J, Lee S, Elmquist J (2010) Melanocortin-4 receptor expression in a vago-vagal circuitry involved in postprandial functions. J Comp Neurol 518:6-24

Guan X, Shi X, Li X, Chang B, Wang Y, Li D, Chan L (2012) GLP-2 receptor in POMC neurons suppresses feeding behavior and gastric motility. Am J Physiol Endocrinol Metab 303:E853E864

Hinney A, Volckmar A-L et al (2013) Melanocortin-4 receptor in energy homeostasis and obesity pathogenesis. Prog Mol Biol Transl Sci 114:147-191

Horstmann A, Kovacs P et al (2013) Common genetic variation near MC4R has a sex-specific impact on human brain structure and eating behavior. PLoS One 8(9):e74362

Loos R (2011) The genetic epidemiology of melanocortin 4 receptor variants. Eur J Pharmacol 660:156-164

Loos RJ, Lindgren CM et al (2008) Common variants near MC4R are associated with fat mass, weight and risk of obesity. Nat Genet 40(6):768-775

Marcadenti A, Fuchs FD, Matte U, Sperb F, Moreira LB, Fuchs SC (2013) Effects of FTO RS9939906 and MC4R RS17782313 on obesity, type 2 diabetes mellitus and blood pressure in patients with hypertension. Cardiovasc Diabetol 12:103-110

Papathanasopoulos A, Camilleri M, Carlson P, Vella A, Nord SJ, Burton D et al (2010) A preliminary candidate genotypeintermediate phenotype study of satiation and gastric motor function in obesity. Obesity 18:1201-1211

Qi L, Kraft P, Hunter D, Hu F (2008) The common obesity variant near MC4R gene is associated with higher intakes of total energy 
and dietary fat, weight change and diabetes risk in women. Hum Mol Genet 17:3502-3508

Rossi J, Balthasar N, Olson D, Scott M, Berglund E, Lee CE et al (2011) Melanocortin-4 receptors expressed by cholinergic neurons regulate energy balance and glucose homeostasis. Cell Metab 13:195-204

Rowland N, Schaub J et al (2010) Effect of MTII on food intake and brain c-Fos in melanocortin-3, melanocortin-4, and double MC3 and MC4 receptor knockout mice. Peptides 31(12):2314-2317

Scherag A, Jarick I, Grothe J, Biebermann H, Scherag S, Volckmar $\mathrm{AL}$ et al (2010) Investigation of a genome wide association signal for obesity: synthetic association and haplotype analyses at the melanocortin 4 receptor gene locus. PLoS One 15:e13967e13975

Sohn J-W, Harris L, Berglund E, Liu T, Vong L, Lowell BB et al (2013) Melanocortin 4 receptors reciprocally regulate sympathetic and parasympathetic preganglionic neurons. Cell 152:612-619

Stutzmann F, Cauchi S, Durand E, Calvacanti-Proença C, Pigeyre M, Hartikainen AL et al (2009) Common genetic variation near $\mathrm{MC} 4 \mathrm{R}$ is associated with eating behaviour patterns in European populations. Int J Obes 33:373-378

TaqMan ${ }^{\circledR}$ SNP Genotyping Assays (2012) Applied Biosystems Inc., Foster City, CA, catalog \# C_32667060_10

Tschritter O, Haupt A et al (2011) An obesity risk SNP (rs17782313) near the MC4R gene is associated with cerebrocortical insulin resistance in humans. J Obes 2011:283153

Valette M, Poitou C, Le Beyec J, Bouillot J-L, Clement K, Czernichow S (2012) Melanocortin-4 receptor mutations and polymorphisms do not affect weight loss after bariatric surgery. PLoS One 7:e48221-e48226

Valette M, Bellisle F, Carette C, Poitou C, Dubern B, Paradis G et al (2013) Eating behaviour in obese patients with melanocortin-4 receptor mutations: a literature review. Int J Obes 37:1027-1035
Valladares M, Domínguez-Vásquez P, Obregón A, Weisstaub G, Burrows R, Maiz A et al (2010) Melanocortin-4 receptor gene variants in Chilean families: association with childhood obesity and eating behavior. Nutr Neurosci 13:71-78

Vazquez Roque M, Camilleri M, Stephens D, Jensen MD, Burton DD, Baxter KL et al (2006) Gastric sensorimotor functions and hormone profile in normal weight, overweight, and obese people. Gastroenterology 131:1717-1724

Vazquez-Roque M, Camilleri M, Vella A, Carlson P, Laugen J, Zinsmeister A (2011) Association of genetic variation in cannabinoid mechanisms and gastric motor functions and satiation in overweight and obesity. Neurogastroenterol Motil 23(637-648):e257

Vogel C, Boes T, Reinehr T, Roth CL, Scherag S, Scherag A et al (2011) Common variants near MC4R: exploring gender effects in overweight and obese children and adolescents participating in a lifestyle intervention. Obes Facts 4:67-75

Wan S, Browning K, Coleman F, Sutton G, Zheng H, Butler A et al (2008) Presynaptic melanocortin-4 receptors on vagal afferent fibers modulate the excitability of rat nucleus tractus solitarius neurons. J Neurosci 28:4957-4966

Xi B, Chandak G, Shen Y, Wang Q, Zhou D (2012) Association between common polymorphism near the MC4R gene and obesity risk: a systematic review and meta-analysis. PLoS One 7:e45731-e45737

Zhou L, Sutton G, Rochford J, Semple RK, Lam DD, Oksanen LJ et al (2007) Serotonin 2C receptor agonists improve type 2 diabetes via melanocortin-4 receptor signaling pathways. Cell Metab 6:398-405 